\title{
Thermal Stability and Decomposition Kinetics of Polysuccinimide
}

\author{
Li Zhang, Mingxing Huang, Cairong Zhou \\ ${ }^{1}$ School of Chemical Engineering and Energy, Zhengzhou University, Zhengzhou, China \\ Email: zhanglizibo@163.com, zhoucairong@zzu.edu.cn
}

Received November 5, 2013; revised December 1, 2013; accepted December 9, 2013

Copyright (C) 2013 Li Zhang et al. This is an open access article distributed under the Creative Commons Attribution License, which permits unrestricted use, distribution, and reproduction in any medium, provided the original work is properly cited.

\begin{abstract}
The thermal stability and decomposition kinetics of polysuccinimide (PSI) were investigated using analyzer DTG-60 under high purity nitrogen atmosphere at different heating rates $(3,6,9,12 \mathrm{~K} / \mathrm{min})$. The thermal decomposition mechanism of PSI was determined by Coats-Redfern method. The kinetic parameters such as activation energy $(E)$, pre-exponential factor $(A)$ and reaction order $(n)$ were calculated by Flynn-Wall-Ozawa and Kissinger methods. The results show that the thermal decomposition of PSI under nitrogen atmosphere mainly occurs in the temperature range of 619.15 - $693.15 \mathrm{~K}$, the reaction order $(n)$ was $\frac{3}{4}$, the activation energy $(E)$ and pre-exponential factor $(A)$ were obtained to be $106.585 \mathrm{~kJ} / \mathrm{mol}$ and $4.644 \times 10^{9} \mathrm{~min}^{-1}$, the integral and differential forms of the thermal decomposition mechanism of PSI were found to be $[-\ln (1-\alpha)]^{3 / 4}$ and $\frac{4}{3}(1-\alpha)[-\ln (1-\alpha)]^{1 / 4}$, respectively. The results play an important role in understanding the thermodynamic properties of polysuccinimide.
\end{abstract}

Keywords: Polysuccinimide; Thermal Gravimetric Analysis; Thermal Stability; Decomposition Kinetics

\section{Introduction}

Polyaspartic acid (PASP, CAS181828-06-8) has amino and carboxyl groups, which belongs to the biological macromolecule material and is a kind of polymer of amino acids. Since it has the characteristics of good biocompatibility and biodegradability, PASP has been widely used in industrial and medical fields as a new type of green chemicals [1]. Polysuccinimide (PSI, CAS689903-2) is the intermediate of PASP. The experimental formula and relative molecular mass of its monomer are $\mathrm{C}_{4} \mathrm{H}_{3} \mathrm{O}_{2} \mathrm{~N}$ and $97.074 \mathrm{~g} / \mathrm{mol}$, respectively. The chemical structure of the monomer can be written as:

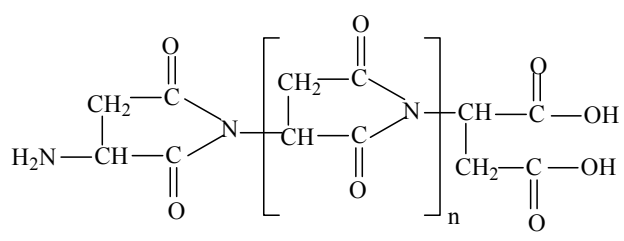

In view of this, PSI is a kind of linear polyimide with high activity and it is easy to open ring changing into poly asparagine with side chains. With the special property, many kinds of derivatives that were used as drug carriers have been prepared [2].

The thermal stability and decomposition kinetics of Polysuccinimide (PSI) were investigated by TG-DTA method. Kinetic parameters such as activation energy (E) and pre-exponential factor (A) were calculated by FlynnWall-Ozawa (F-W-O) and Kissinger methods. The kinetic mechanism function of thermal decomposition of PSI was established by Coats-Redfern method. Using TG-DTA method to study the stability of drugs has the advantages of less sample dose, short experimental period and reliable results. These data not only play an active role in understanding the thermodynamic properties of PSI but also provide a theoretical basis for practical application.

\section{Experimental}

\subsection{Materials and Instruments}

Polysuccinimide (the mass fraction was higher than 99.5\%) was purchased from Henan Xinlianxin Fertilizer Limited 
Co. $\alpha-\mathrm{Al}_{2} \mathrm{O}_{3}$ (standard material, Shimadu Company in Japan) was used as standard material in the process of thermal analysis.

The TG-DTA analyzer (type DTG-60, Shimadzu Corporation, Japan) was used to determine the TG-DTA curves of the sample. SPN-500-type nitrogen generator (Hewleet-Packard, Beijing Institute of Technology, China) was used to provide a high purity nitrogen atmosphere for the experimental system of thermal analysis. Fourier Transform Infrared Spectrometer (type WQF, Beijing Beifen-Ruili Analytical Instrument (Group) Co, Ltd) was used to analyze PSI. Gel permeation chromatography (type Agilent1100, Agilent Corporation, America) was used to analyze PSI's purity and the number-average molecular weight $\left(M_{n}\right)$ and polydispesity index $\left(M_{w} / M_{n}\right)$.

\subsection{Experiment Methods}

The PSI sample was dried in the vacuum oven at 378.15 $\mathrm{K}$ before analysis. The thermogravimetric measurements were carried out at different heating rates $(3,6,9,12$ $\mathrm{K} / \mathrm{min}$ ) from room temperature to $873.15 \mathrm{~K}$ under high purity nitrogen atmosphere $(20 \mathrm{ml} / \mathrm{min})$. Mass of each powdered sample was about 4 - $5 \mathrm{mg}$.

\subsection{Characterization of PSI}

\subsubsection{FTIR Analysis of PSI}

FTIR spectra of PSI were recorded in the wave number range of $4000-500 \mathrm{~cm}^{-1}$. The result is shown in Figure 1. From Figure 1, we can know that the carboxyl group of branched chain in the opened ring appears at 1400 $\mathrm{cm}^{-1}$, the carbon-carbon bond appears at $1165 \mathrm{~cm}^{-1}$, the coupled carbonyl group appears at $1720 \mathrm{~cm}^{-1}$ and the carbonyl group in the ring obviously appears at 1797 $\mathrm{cm}^{-1}$.

\subsubsection{Gel Permeation Chromatography Analysis of PSI}

The analysis diagram of PSI by gel permeation chromatography is shown in Figure 2. The analysis results show

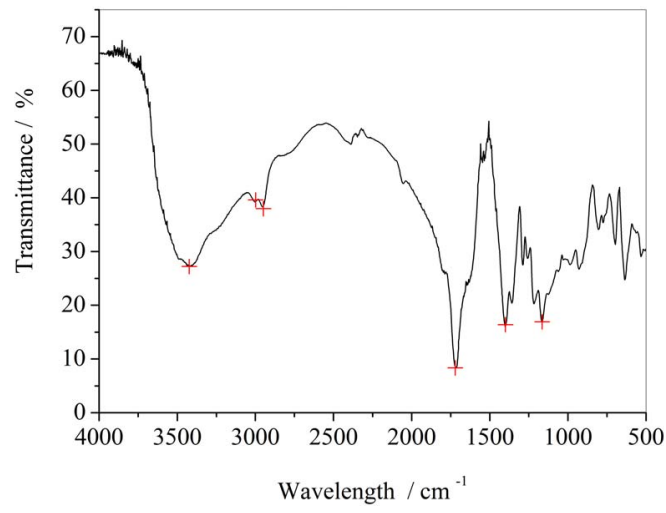

Figure 1. FTIR spectra of PSI.

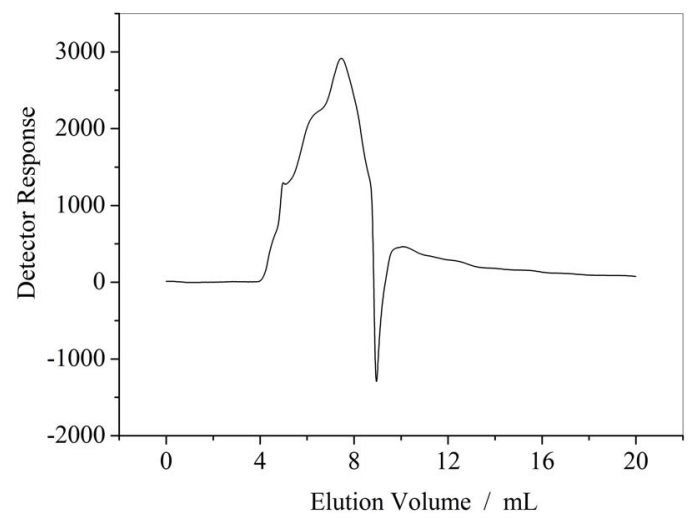

Figure 2. The analysis diagram of PSI by gel permeation chromatography.

that the number-average molecular weight $\left(M_{n}\right)$ of PSI is $2.7941 \times 10^{4} \mathrm{~g} / \mathrm{mol}$, the polydispersity index of relative molecular mass $\left(M_{w} / M_{n}\right)$ of PSI is 21.644 and Polymerization degree of PSI is obtained to be 287.5.

\subsection{Theoretical Analysis}

There are two major categories to study the thermal decomposition kinetics of polymer, which are differential method and integral method. The differential method contains Kissinger [3-5], Caroll-Freeman [6] and Friedman [7] methods while Coats-Redfern [8-12], Doyle [13] and Flynn-Wall-Ozawa (F-W-O) [14-16] methods belong to the integral method. Coats-Redfern, Flynn-Wall-Ozawa (F-W-O) and Doyle methods are usually used for investigating thermal decomposition kinetics of polymers.

In general, the thermal decomposition of a solid polymer under inert atmosphere can be summarized as: $B_{\text {solid }}$ $\rightarrow C_{\text {solid }}+D_{\text {gas }}$. Polymer is finally decomposed into solid residue $(C)$ and gaseous matter $(D)$.

The kinetic analysis of solid-state sample is usually given by Equation (1) [17]

$$
r=\frac{\mathrm{d} \alpha}{\mathrm{d} t}=K(T) f(\alpha)
$$

where $\frac{\mathrm{d} \alpha}{\mathrm{d} t}$ is the rates of conversion; $\alpha$ is the conversion degree that can be defined as $\alpha=\frac{m_{o}-m_{t}}{m_{o}-m_{f}}$ in which $m_{0}$ and $m_{f}$ are the initial and final masses of the sample, respectively; $m_{t}$ is the mass of the sample at time $t$ (or temperature $T$ ) of the decomposition process, mg. In Equation (1), $k(T)$ is the temperature dependent rates constant and is normally assumed to obey the Arrhenius equation:

$$
k(T)=A \mathrm{e}^{-\frac{E}{R T}}
$$

where $A$ is the pre-exponential factor $\left(\mathrm{min}^{-1}\right), E$ is the 
activation energy $(\mathrm{kJ} / \mathrm{mol})$ of the kinetic process, $R$ is the gas constant $(8.314 \mathrm{~J} /(\mathrm{mol} \cdot \mathrm{K}))$ and $T$ is the absolute temperature $(\mathrm{K})$.

Moreover, taking into account the heating rates $\beta=$ $\mathrm{d} T / \mathrm{d} t$ under non-isothermal condition, $\frac{\mathrm{d} \alpha}{\mathrm{d} t}$ can be described by Equation (3):

$$
\frac{\mathrm{d} \alpha}{\mathrm{d} t}=\left(\frac{\mathrm{d} \alpha}{\mathrm{d} T}\right)\left(\frac{\mathrm{d} T}{\mathrm{~d} t}\right)=\beta \frac{\mathrm{d} \alpha}{\mathrm{d} T}
$$

Equation (4) can be obtained by combing Equations (1)-(3), which describes the thermal decomposition kinetics. Based on TGA data, the kinetic parameters can be calculated from Equation (4). [18]:

$$
\frac{\mathrm{d} a}{\mathrm{~d} t}=\frac{A}{\beta} \mathrm{e}^{-\frac{E}{R T}} f(\alpha)
$$

\subsubsection{Kissinger Method}

The formula of Kissinger method is given by Equation (5) [3-5]:

$$
\ln \frac{\beta_{i}}{T_{p i}^{2}}=\ln \left(\frac{A_{k} R}{E_{k}}\right)-\frac{E_{k}}{R} \frac{1}{T_{p i}}
$$

where $i=1,2,3,4$ (or even more); $T_{p i}$ is the peak temperatures of different DTA curve at different heating rates. By plotting $\ln \left(\beta_{i} / T_{p i}^{2}\right)$ versus $1 / T_{p i}$, the activation energy $E_{k}$ and pre-exponential factor $A_{k}$ can be calculated based on its slope $\left(-E_{k} / R\right)$ and intercept $\ln \left(A_{k} R / E_{k}\right)$, respectively.

\subsubsection{Flynn-Wall-Ozawa (F-W-O) Method}

F-W-O method can be used directly to calculate the activation energy $E$. The integral formula of F-W-O method [14-16] is showed in Equation (6):

$$
\lg \beta=\lg \left(\frac{A E}{R g(\alpha)}\right)-2.315-0.4567\left(\frac{E}{R T}\right)
$$

In Equation (6), since the value of $\lg (A E /(\operatorname{Rg}(\alpha)))$ is approximately constant when the values of $\alpha$ are the same at the different heating rates $\beta_{i}$, so it is easy to obtain values of $E$ by plotting $\lg \beta$ against $1 / T$ at the certain conversion degree $\alpha$.

\subsubsection{Coats-Redfern Method}

Coats-Redfern method can be described as Equation (7). [8-10,12]:

$$
\ln \frac{g(\alpha)}{T_{i}^{2}}=\ln \frac{A_{c} R}{\beta_{i} E}-\frac{E_{c}}{R T_{i}}
$$

where $g(\alpha)$ comes from one of 34 forms of integral formula in the literature which are shown in Table 1 [11]. From Equation (7), the values of both $E_{c}$ and $A_{c}$ can be obtained for any selected $g(\alpha)$ and fixed $\beta_{i}(i=1,2,3,4$, even more). The calculating steps in detail are: 1) choose the same $\alpha_{j}$ for each heating rates $\beta_{i}$ and calculate the corresponding $\left.g\left(\alpha_{i j}\right) ; 2\right)$ give the corresponding temperature $T_{i j}$ according to $\left.\alpha_{i j} ; 3\right)$ describe the sketch of $\ln \frac{g(\alpha)}{T_{i}^{2}}$ versus $1 / T_{i}$ for each fixed $\beta_{i}$, and calculate the values of both $E_{c}$ and $\ln \left(A_{c}\right)$ according to the slope and intercept of the line, respectively; 4) determine the mechanism function of the thermal decomposition process. Generally, the selected mechanism functions should meet all the conditions, which are: 1) $0<E_{c}<400 \mathrm{~kJ} / \mathrm{mol}$; 2)

$\left|\left(E_{0}-E_{c}\right) / E_{0}\right| \leq 0.3$ where $E_{0}$ come from F-W-O method 3) $\left|\left(\ln A_{c}-\ln A_{k}\right) / \ln A_{c}\right| \leq 0.3$ in which $\ln \left(A_{k}\right)$ are obtained from Kissinger method. If $g(\alpha)$ meet the requirements mentioned above, $g(\alpha)$ can be regarded as the probable mechanism function for the thermal decomposition process.

\subsection{Determination of High Temperature Heat-Resistance of PSI}

The activation energy data obtained by above-mentioned methods can be used to evaluate the high temperature heat-resistance of PSI. The relationship between activa-

Table 1. 34 types of thermal decomposition mechanism functions.

\begin{tabular}{cccc}
\hline$N_{O}$ & $g(\alpha)$ & $N_{O}$ & $g(\alpha)$ \\
\hline $1-6$ & $\alpha^{n} n=\frac{1}{4}, \frac{1}{3}, \frac{1}{2}, 1,2, \frac{3}{2}$ & 27 & $(1-\alpha)^{-1}-1$ \\
7 & $\alpha+(1-\alpha) \ln (1-\alpha)$ & 28 & $(1-\alpha)^{-1 / 2}$ \\
8 & $\left(1-\frac{2}{3} \alpha\right)-(1-\alpha)^{3 / 2}$ & 29 & $(1-\alpha)^{-2}$ \\
$9-19$ & {$[-\ln (1-\alpha)]^{n} n=\frac{1}{2}, \frac{1}{4}, \frac{1}{3}, \frac{2}{5}, \frac{2}{3}, \frac{3}{4}, 1, \frac{3}{2}, 2,3,4$} & $30-31$ & {$\left[1-(1-\alpha)^{1 / 2}\right]^{n} n=\frac{1}{2}, 2$} \\
$20-25$ & $1-(1-\alpha)^{n} n=\frac{1}{4}, \frac{1}{3}, \frac{1}{2}, 2,3,4$ & $32-33$ & {$\left[1-(1-\alpha)^{1 / 3}\right]^{n} n=\frac{1}{2}, 2$} \\
26 & $(1-\alpha)^{-1}$ & 34 & {$\left[(1+\alpha)^{1 / 3}-1\right]^{2}$} \\
\hline
\end{tabular}


tion energy and lifetime of polymer can be expressed by Equation (8) [19]:

$$
\ln t_{f}=\frac{E}{R T_{f}}+\ln \frac{E}{\beta R} \cdot P\left(\frac{E}{R T_{\alpha}}\right)
$$

where $t_{f}$ is the lifetime of PSI at the temperature of $T_{f}, T_{\alpha}$ is the temperature at the conversion degree $\alpha$. Combined Equations (4) and (8), $T_{f}$ can be shown as:

$$
T_{f}=\frac{E R^{-1}}{\ln \left(\frac{A t_{f}}{|\ln (1-\alpha)|}\right)}
$$

\section{Results and Discussion}

\subsection{Thermal Decomposition of PSI}

TG and DTA curves of PSI sample are shown in Figures 3 and 4 . The thermal analysis data are summarized in Table 2. In Figure 3, the thermal decomposition temperature at different heating rates increases with the increasing of $\beta$. That indicates the decomposition temperature is affected by the heating rate $\beta$. Besides, each TG curve of PSI under nitrogen atmosphere has an obvious mass loss process where percentage of mass loss

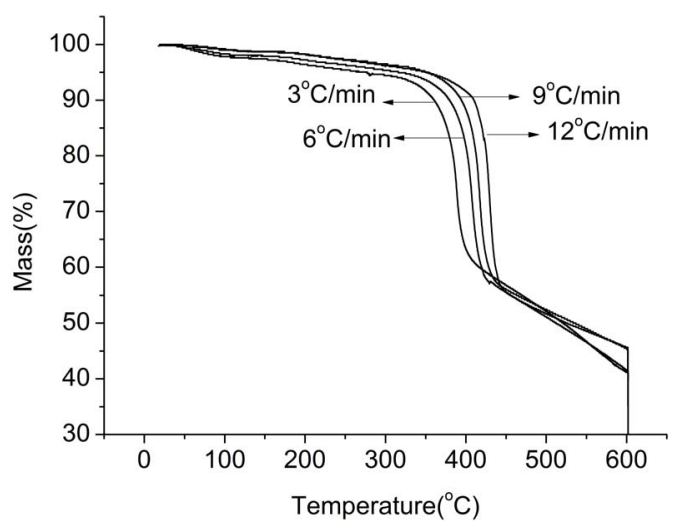

Figure 3. The TG curves of PSI in nitrogen atmosphere.

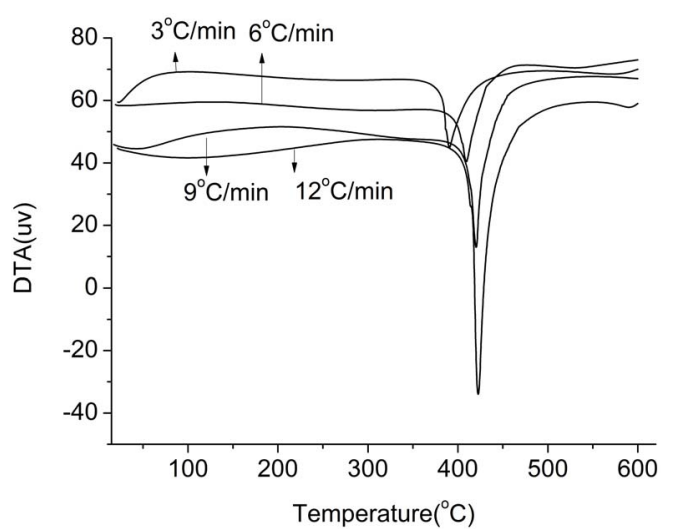

Figure 4. The DTA curves of PSI in nitrogen atmosphere.
Table 2. Basic data of kinetics of PSI from TG.

\begin{tabular}{ccccc}
\hline$\beta /\left(\mathrm{K} \cdot \mathrm{min}^{-1}\right)$ & $T_{p} / \mathrm{K}$ & $\left(1 / T_{p}\right) / \mathrm{K}^{-1}$ & $\frac{\mathrm{FWO}}{\ln \beta}$ & $\frac{\text { Kissinger }}{\ln \left(\beta / T_{p}^{2}\right)}$ \\
\hline 3 & 663.94 & 0.001516 & 1.099 & -11.898 \\
6 & 682.76 & 0.001473 & 1.792 & -11.261 \\
9 & 693.17 & 0.001451 & 2.197 & -10.885 \\
12 & 696.97 & 0.001444 & 2.485 & -10.609 \\
\hline
\end{tabular}

increases gradually with the increasing of heating rates and TG curve moves toward to the right.

From Figures 3 and 4, the thermal decomposition of PSI under nitrogen atmosphere mainly occurs in the temperature range of 619.15 to $693.15 \mathrm{~K}$. Mass loss is accompanied by heat absorption, so thermal decomposition process and solid rearrangement reaction may simultaneously happen in this process.

\subsection{Non-Isothermal Kinetic of PSI}

Plots of $\ln \frac{\beta}{T_{p}^{2}}$ against $1 / T_{p}$ of PSI by Kissinger method is shown in Figure 5. The values of activation energy $E_{k}$ and exponential factor $\ln \left(A_{k}\right)$ calculated by Kissinger method are $143.874 \mathrm{~kJ} / \mathrm{mol}$ and $23.897 \mathrm{~min}^{-1}$, respectively. The linear correlation coefficient $\left(R^{2}\right)$ is 0.9852 .

The activation energies calculated at different conversion degree using Flynn-Wall-Ozawa method are shown in Table 3 and the relationship between $E_{0}$ and conversion degree $\alpha$ are showed in Figure 6.

The results show that the correlation coefficients $\left(R^{2}\right)$ of FWO method is better, the values of activation energy is between 81.509 and $122.205 \mathrm{~kJ} / \mathrm{mol}$ and increase with the increasing of conversion degree. From Table 3 and Figure 6, the average value of activation energy $E_{o}$ is $104.202 \mathrm{~kJ} / \mathrm{mol}$ and the pre-exponential factor $\lg A_{o}$ is 9.967.

The kinetic parameters calculated by Coats-Redfern method are listed in Table 4 . The values of activation energy and exponential factor calculated by Coats-Redfern method compare respectively with the average value of activation energy calculated using FWO method and the value of pre-exponential factor obtained by Kissinger method, the results are listed in Table 5.

The thermal decomposition process of PSI in the temperature stage of 619.15 to $693.15 \mathrm{~K}$ is consistent with the sequence number 14 in Table 1, this is because $E_{c}$ and $\ln \left(A_{c}\right)$ meet better with the conditions of both $\left|\left(E_{0}-E_{c}\right) / E_{0}\right| \leq 0.3$ and $\left|\left(\ln A_{c}-\ln A_{k}\right) / \ln A_{c}\right| \leq 0.3$ than others; besides, the relative coefficients $\left(R^{2}\right)$ are much better. The integral and differential forms of the mechanism function are $g(\alpha)=[-\ln (1-\alpha)]^{3 / 4}$ and $f(\alpha)=\frac{4}{3}(1-\alpha)[-\ln (1-\alpha)]^{1 / 4}$, respectively. The 
values of $E_{c}$ and $\ln \left(A_{c}\right)$ are obtained to be $108.967 \mathrm{~kJ} / \mathrm{mol}$ and $16.802 \mathrm{~min}^{-1}$. So the activation energy and pre-exponential factor of thermal decomposition process of PSI can be regarded as $106.585 \mathrm{~kJ} / \mathrm{mol}$ and $4.644 \times 10^{9} \mathrm{~min}^{-1}$ (i.e. average values obtained by the Coats-Redfern and FWO methods). The thermal decomposition kinetic equation of PSI can be described as:

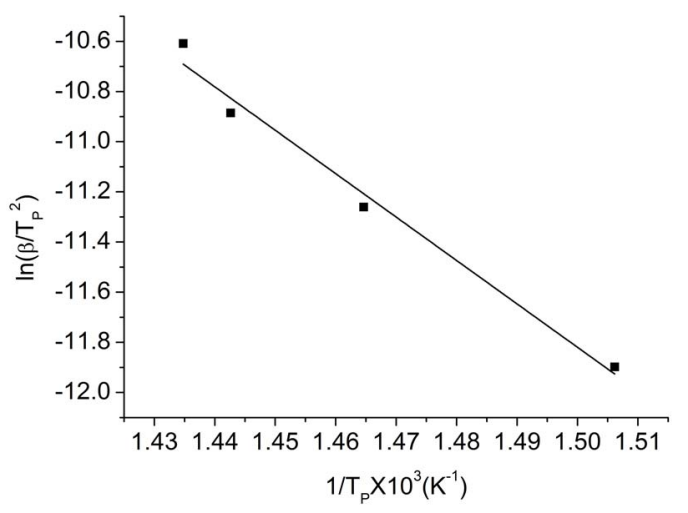

Figure 5. Plots of $\ln \frac{\beta}{T_{p}^{2}}$ and $1 / T_{p}$ of PSI of Kissinger method.
Table 3. The activation energy $E_{o}$ and exponential factor $\lg A_{o}$ of PSI.

\begin{tabular}{cccc}
\hline$\alpha$ & $E_{o}(\mathrm{~kJ} / \mathrm{mol})$ & $\lg A_{o}\left(\mathrm{~min}^{-1}\right)$ & $R^{2}$ \\
\hline 0.15 & 81.509 & 8.134 & 0.9853 \\
0.20 & 95.987 & 9.285 & 0.9895 \\
0.25 & 106.373 & 10.131 & 0.9885 \\
0.30 & 114.936 & 10.839 & 0.9902 \\
0.35 & 122.205 & 11.447 & 0.9912 \\
Mean $^{*}$ & 104.202 & 9.967 & 0.9889 \\
\hline
\end{tabular}

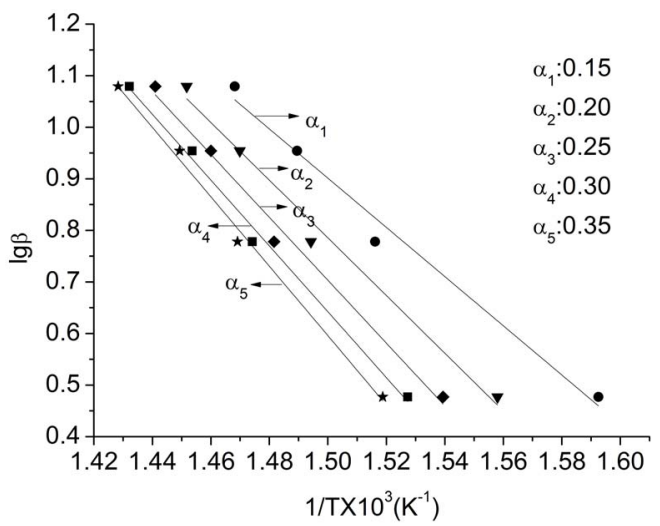

Figure 6. FWO curves of PSI at different conversion.

Table 4. Results of 34 types of kinetic equations of PSI calculated with Coats-Redfern method.

\begin{tabular}{|c|c|c|c|c|c|c|c|c|c|c|c|c|}
\hline \multirow[b]{2}{*}{ No } & \multicolumn{3}{|c|}{$\beta=3 \mathrm{~K} / \mathrm{min}$} & \multicolumn{3}{|c|}{$\beta=6 \mathrm{~K} / \mathrm{min}$} & \multicolumn{3}{|c|}{$\beta=9 \mathrm{~K} / \mathrm{min}$} & \multicolumn{3}{|c|}{$\beta=12 \mathrm{~K} / \mathrm{min}$} \\
\hline & $E_{c} /\left(\mathrm{kJ} \cdot \mathrm{mol}^{-1}\right)$ & $\ln A_{c}$ & $R^{2}$ & $E_{c} /\left(\mathrm{kJ} \cdot \mathrm{mol}^{-1}\right)$ & $\ln A_{c}$ & $R^{2}$ & $E_{c} /\left(\mathrm{kJ} \cdot \mathrm{mol}^{-1}\right)$ & $\ln A_{c}$ & $R^{2}$ & $E_{c} /\left(\mathrm{kJ} \cdot \mathrm{mol}^{-1}\right)$ & $\ln A_{c}$ & $R^{2}$ \\
\hline 1 & 12.759 & -2.491 & 0.926 & 25.349 & 0.969 & 0.948 & 26.880 & 1.676 & 0.951 & 31.494 & 2.782 & 0.969 \\
\hline 2 & 20.575 & -0.678 & 0.948 & 37.511 & 3.417 & 0.957 & 39.043 & 4.106 & 0.959 & 45.789 & 5.520 & 0.976 \\
\hline 4 & 83.094 & 11.400 & 0.970 & 134.812 & 21.146 & 0.970 & 136.341 & 21.806 & 0.970 & 160.144 & 25.684 & 0.986 \\
\hline 5 & 176.872 & 28.178 & 0.973 & 280.755 & 46.555 & 0.972 & 282.285 & 47.209 & 0.972 & 331.679 & 54.781 & 0.987 \\
\hline 6 & 129.981 & 19.859 & 0.972 & 207.783 & 33.917 & 0.971 & 209.313 & 34.573 & 0.971 & 245.912 & 40.298 & 0.987 \\
\hline 7 & 185.510 & 29.230 & 0.971 & 294.174 & 48.401 & 0.970 & 295.704 & 49.054 & 0.970 & 347.600 & 56.992 & 0.986 \\
\hline 8 & 71.090 & 8.701 & 0.977 & 116.155 & 17.352 & 0.977 & 117.685 & 18.013 & 0.977 & 138.012 & 21.381 & 0.990 \\
\hline 9 & 43.011 & 4.068 & 0.954 & 72.413 & 10.150 & 0.957 & 73.945 & 10.820 & 0.958 & 86.931 & 13.140 & 0.976 \\
\hline 10 & 16.162 & -1.586 & 0.922 & 30.638 & 2.140 & 0.941 & 32.169 & 2.837 & 0.944 & 37.771 & 4.089 & 0.964 \\
\hline 11 & 25.112 & 0.413 & 0.941 & 44.563 & 4.898 & 0.950 & 46.094 & 5.581 & 0.952 & 54.157 & 7.189 & 0.971 \\
\hline 12 & 32.272 & 1.911 & 0.948 & 55.703 & 7.028 & 0.954 & 57.234 & 7.704 & 0.955 & 67.267 & 9.597 & 0.974 \\
\hline 13 & 60.910 & 7.532 & 0.959 & 100.267 & 15.243 & 0.960 & 101.797 & 15.907 & 0.960 & 119.705 & 18.940 & 0.979 \\
\hline 14 & 69.859 & 9.227 & 0.960 & 114.193 & 17.756 & 0.961 & 115.723 & 18.418 & 0.961 & 136.092 & 21.807 & 0.979 \\
\hline 15 & 96.708 & 14.227 & 0.963 & 155.962 & 25.218 & 0.962 & 157.492 & 25.876 & 0.963 & 185.253 & 30.333 & 0.981 \\
\hline 17 & 204.100 & 33.672 & 0.966 & 323.065 & 54.547 & 0.965 & 324.595 & 55.201 & 0.965 & 381.895 & 63.929 & 0.983 \\
\hline 18 & 311.492 & 52.793 & 0.967 & 490.168 & 83.565 & 0.966 & 491.698 & 84.218 & 0.966 & 578.538 & 97.216 & 0.983 \\
\hline 19 & 418.884 & 71.787 & 0.968 & 657.272 & 112.460 & 0.966 & 658.801 & 113.111 & 0.966 & 775.181 & 130.378 & 0.983 \\
\hline 20 & 93.175 & 12.110 & 0.965 & 150.483 & 22.778 & 0.964 & 152.013 & 23.437 & 0.965 & 178.743 & 27.744 & 0.982 \\
\hline 21 & 92.019 & 12.158 & 0.965 & 148.679 & 22.720 & 0.965 & 150.209 & 23.379 & 0.965 & 176.606 & 27.637 & 0.983 \\
\hline 22 & 89.733 & 12.089 & 0.966 & 145.129 & 22.442 & 0.966 & 146.659 & 23.101 & 0.966 & 172.383 & 27.261 & 0.983 \\
\hline 23 & 70.820 & 9.515 & 0.977 & 115.731 & 18.140 & 0.977 & 117.261 & 18.802 & 0.977 & 137.522 & 22.161 & 0.990 \\
\hline 24 & 59.848 & 7.583 & 0.983 & 98.679 & 15.209 & 0.983 & 100.209 & 15.873 & 0.983 & 117.319 & 18.771 & 0.994 \\
\hline 25 & 50.119 & 5.764 & 0.989 & 83.547 & 12.505 & 0.989 & 85.077 & 13.172 & 0.990 & 99.419 & 15.665 & 0.997 \\
\hline 26 & 17.893 & -0.548 & 0.787 & 33.271 & 3.307 & 0.833 & 34.802 & 4.001 & 0.843 & 41.333 & 5.412 & 0.876 \\
\hline 27 & 111.674 & 17.306 & 0.956 & 179.217 & 29.666 & 0.955 & 180.746 & 30.323 & 0.956 & 212.872 & 35.419 & 0.976 \\
\hline 28 & 3.604 & -4.956 & 0.378 & 11.067 & -1.911 & 0.689 & 12.597 & -1.133 & 0.735 & 14.972 & -0.329 & 0.761 \\
\hline 29 & 46.471 & 6.017 & 0.861 & 77.680 & 12.390 & 0.871 & 79.211 & 13.059 & 0.875 & 94.056 & 15.685 & 0.908 \\
\hline 30 & 39.523 & 2.951 & 0.957 & 66.993 & 8.721 & 0.961 & 68.525 & 9.392 & 0.961 & 80.498 & 11.564 & 0.979 \\
\hline 31 & 190.149 & 29.474 & 0.970 & 301.391 & 49.070 & 0.968 & 302.921 & 49.724 & 0.969 & 356.163 & 57.858 & 0.985 \\
\hline 32 & 40.667 & 3.002 & 0.956 & 68.771 & 8.874 & 0.959 & 70.302 & 9.545 & 0.960 & 82.608 & 11.765 & 0.978 \\
\hline
\end{tabular}


Table 5. Calculation of 6 types of kinetics equations for PSI with Coats-Redfern method.

\begin{tabular}{|c|c|c|c|c|c|c|}
\hline Sequence number of mechanism function $g(\alpha)$ & $\begin{array}{c}\beta \\
\mathrm{K} / \mathrm{mol}\end{array}$ & $\begin{array}{c}E_{c} \\
\mathrm{~kJ} / \mathrm{mol}\end{array}$ & $\begin{array}{c}\ln A_{c} \\
\min ^{-1}\end{array}$ & $R^{2}$ & $\left|\frac{E_{o}-E_{c}}{E_{o}}\right|$ & $\frac{\ln A_{c}-\ln A_{k}}{\ln A_{k}}$ \\
\hline 4 & 3 & 83.094 & 11.400 & 0.970 & 0.203 & 0.523 \\
\hline 4 & 6 & 134.812 & 21.146 & 0.970 & 0.294 & 0.115 \\
\hline 4 & 9 & 136.341 & 21.806 & 0.970 & 0.308 & 0.088 \\
\hline 4 & 12 & 160.144 & 25.684 & 0.986 & 0.537 & 0.075 \\
\hline 8 & 3 & 71.090 & 8.701 & 0.977 & 0.318 & 0.636 \\
\hline 8 & 6 & 116.155 & 17.352 & 0.977 & 0.115 & 0.274 \\
\hline 8 & 9 & 117.685 & 18.013 & 0.977 & 0.129 & 0.246 \\
\hline 8 & 12 & 138.012 & 21.381 & 0.990 & 0.324 & 0.105 \\
\hline 13 & 3 & 60.91 & 7.532 & 0.959 & 0.415 & 0.685 \\
\hline 13 & 6 & 100.267 & 15.243 & 0.960 & 0.038 & 0.362 \\
\hline 13 & 9 & 101.797 & 15.907 & 0.960 & 0.023 & 0.334 \\
\hline 13 & 12 & 119.705 & 18.940 & 0.979 & 0.149 & 0.207 \\
\hline 14 & 3 & 69.859 & 9.227 & 0.960 & 0.330 & 0.614 \\
\hline 14 & 6 & 114.193 & 17.756 & 0.961 & 0.096 & 0.257 \\
\hline 14 & 12 & 136.092 & 21.807 & 0.979 & 0.306 & 0.087 \\
\hline 23 & 3 & 70.82 & 9.515 & 0.977 & 0.320 & 0.602 \\
\hline 23 & 6 & 115.731 & 18.140 & 0.977 & 0.111 & 0.241 \\
\hline 23 & 9 & 117.261 & 18.802 & 0.977 & 0.125 & 0.213 \\
\hline 23 & 12 & 137.522 & 22.161 & 0.990 & 0.320 & 0.073 \\
\hline 24 & 3 & 59.848 & 7.583 & 0.983 & 0.426 & 0.683 \\
\hline 24 & 6 & 98.679 & 15.209 & 0.983 & 0.053 & 0.364 \\
\hline 24 & 9 & 100.209 & 15.873 & 0.983 & 0.038 & 0.336 \\
\hline 24 & 12 & 117.319 & 18.771 & 0.994 & 0.126 & 0.215 \\
\hline
\end{tabular}

$$
\frac{\mathrm{d} \alpha}{\mathrm{d} t}=4.644 \times 10^{9} \mathrm{e}^{-106.585 \times 10^{3 / R T}}(1-\alpha)^{3 / 4}
$$

\subsection{High Temperature Heat-Resistance of PSI}

Selecting $t_{f}=60 \mathrm{~s}$ and $\alpha=15 \%$ as the evaluation indexes of the high temperature heat-resistance of the polymer. According to Equation (12), value of $T_{f}$ of PSI in nitrogen atmosphere is $259.27^{\circ} \mathrm{C}$. The result shows that the high temperature heat-resistance of PSI is not very well.

\section{Conclusion}

The thermal behavior of polysuccinimide under nonisothermal condition was investigated using TG-DTA method at different heating rates in nitrogen atmosphere. The results show that the thermal decomposition of PSI under nitrogen atmosphere mainly occurs in the temperature range of $619.15-693.15 \mathrm{~K}$, the reaction order $(n)$ was $3 / 4$, the activation energy $(E)$ and pre-exponential factor $(A)$ were obtained to be $106.585 \mathrm{~kJ} / \mathrm{mol}$ and 4.644 $\times 10^{9} \mathrm{~min}^{-1}$, the integral and differential forms of the thermal decomposition mechanism of PSI were found to be $[-\ln (1-\alpha)]^{3 / 4}$ and $\frac{4}{3}(1-\alpha)[-\ln (1-\alpha)]^{1 / 4}$, respectively.

\section{REFERENCES}

[1] A. W. Yang, G. P. Cao and M. H. Zhang, "Synthesis of Polysuccinimide and Determination of the Intrinsic Vis- cosity," Polymer Materials Science \& Engineering, Vol. 26, 2010, pp. 4-7.

[2] J. H. Jeong, H. S. Kang, S. R. Yang and J. D. Kim, "Polymer Micelle-Like Aggregates of Novel Amphiphilic Biodegradable Poly(Asparagine) Grafted with Poly(Caprolactone)," Polymer, Vol. 44, No. 3, 2003, pp. 583-591. http://dx.doi.org/10.1016/S0032-3861(02)00816-9

[3] A. Rotaru, M. Anca, G. Popa, P. Rotaru and E. Segal, "Non-Isothermal Kinetics of 2-Allyl-4-((4-(4-Methylbenzyloxy)Phenyl) Diazenyl) Phenol in Air Flow," Journal of Thermal Analysis and Calorimetry, Vol. 97, No. 2, 2009, pp. 485-491. http://dx.doi.org/10.1007/s10973-009-0214-1

[4] H. E. Kissinger, "Variation of Peak Temperature with Heating Rate in Different Rate in Differential Thermal Analysis," Journal of Research of the National Bureau of Standards, Vol. 57, No. 4, 1956, pp. 217-221. http://dx.doi.org/10.6028/jres.057.026

[5] H. E. Kissinger, "Reaction Kinetic in Differential Thermal Analysis," Analytical Chemistry, Vol. 29, No. 11, 1957, pp. 1702-1706. http://dx.doi.org/10.1021/ac60131a045

[6] E. S. Freeman and B. Carroll, "The Application of Thermoanalytical Technique to Reaction Kinetics," Journal of Physical Chemistry, Vol. 3, 1958, pp. 394-397.

[7] H. L. Friedman, "Kinetics and Gaseous Products of Thermal Decomposition of Polymers," Journal of Macromolecular Science: Part A-Chemistry, Vol. 1, No. 1, 1967, pp. 57-59. http://dx.doi.org/10.1080/10601326708053917

[8] A. W. Coats and J. P. Redfern, "Kinetic Parameters from Thermogravimetric Data," Nature, Vol. 201, 1964, pp. 68-69. http://dx.doi.org/10.1038/201068a0 
[9] C. R. Zhou, Q. H. Li and H. F. Wang, "Thermal Analysis for the Thermal Decomposition of Methylsulfonate Tin," Journal of Chemical Engineering of Chinese Universities, Vol. 20, 2006, pp. 669-672.

[10] C. R. Zhou, X. H. Shi, H. F. Wang and D. G. Jiang, "Thermal Decomposition and the Non-Isothermal Decomposition Kinetics of DL-2-Naproxen," Journal of Chemical Engineering of Chinese Universities, Vol. 25, 2011, pp. 442-446.

[11] L. G. Lu, Q. Zhang, X. N. Xu, X. L. Dong and D. W. Wang, "Thermal Degradation Kinetics of Novel Intumescent Flame Retardant Polypropylene," China Plastics, Vol. 23, 2009, pp. 53-60.

[12] C. Y. Ou, C. H. Zhang, S. D. Li, L. Yang and J. J. Dong, "Thermal Degradation Kinetics of Chitosan-Cobalt Complex as Studied by Thermogravimetric Analysis," Carbohydrate Polymers, Vol. 82, No. 4, 2010, pp. 1284-1289. http://dx.doi.org/10.1016/j.carbpol.2010.07.010

[13] C. D. Doyle, "Kinetic Analysis of Thermogravimetric Data," Journal of Applied Polymer Science, Vol. 5, No. 15,1961 , pp. 285-292. http://dx.doi.org/10.1002/app.1961.070051506

[14] T. Ozawa, "Kinetic Analysis of Derivative Curves in Thermal Analysis," Journal of Thermal Analysis, Vol. 2, No. 3, 1970, pp. 301-310. http://dx.doi.org/10.1007/BF01911411

[15] F. X. Chen, C. R. Zhou and G. P. Li, "Study on Thermal
Decomposition and the Non-Isothermal Decomposition Kinetics of Glyphosate," Journal of Thermal Analysis and Calorimetry, Vol. 109, No. 3, 2012, pp. 1457-1462.

[16] Q. F. Wang, L. Wang, X. W. Zhang and Z. T. Mi, “Thermal Stability and Kinetic of Decomposition of Nitrated HTPB," Journal of Hazardous Materials, Vol. 172, No. 2-3, 2009, pp. 1659-1664. http://dx.doi.org/10.1016/j.jhazmat.2009.08.040

[17] C. D. Gamlin, N. K. Dutta, N. R. Choudhury, D. Kehoe and J. Matisons, "Evaluation of Kinetic Parameters of Thermal and Oxidative Decomposition of Base Oils by Conventional, Isothermal and Modulated TGA, and Pressure DSC," Thermochimica Acta, Vol. 392-393, 2002, pp. 357-369. http://dx.doi.org/10.1016/S0040-6031(02)00121-1

[18] X. Y. Li, Y. Q. Wu, D. H. Gu and F. X. Gan, "Thermal Decomposition Kinetics of Nickel(II) and Cobalt(II) Azo Barbituric Acid Complexes," Thermochimica Acta, Vol. 493, No. 1-2, 2009, pp. 85-89. http://dx.doi.org/10.1016/j.tca.2009.04.010

[19] Z. W. Zhou and Q. X. Wu, "Studies on Thermal Properties of Poly(Phenylene Sulfide Amide)," Journal of Applied Polymer Science, Vol. 66, No. 7, 1997, pp. 12271230.

http://dx.doi.org/10.1002/(SICI)1097-4628(19971114)66: 7<1227::AID-APP2>3.0.CO;2-I 